Available online at http://jddtonline.info

RESEARCH ARTICLE

\title{
IN VITRO ANTICANCER EFFECT OF ARTABOTRYS CRASSIFOLIUS HOOK.F. \& THOMSON AGAINST HUMAN CARCINOMA CELL LINES
}

\author{
*Tan Kok Kwan ${ }^{1}$, Bradshaw Tracey D. ${ }^{2}$, Chu Jessica ${ }^{2}$, Khoo Teng Jin ${ }^{1}$, Wiart Christophe ${ }^{1}$ \\ ${ }^{1}$ School of Pharmacy, Faculty of Science, The University of Nottingham Malaysia Campus, Jalan Broga, 43500, \\ Semenyih, Selangor Darul Ehsan, Malaysia.
}

${ }^{2}$ Centre for Biomolecular Sciences, School of Pharmacy, The University of Nottingham, University Park, Nottingham NG7 2RD, UK.

*Corresponding authoremail: khyx1tkk@nottingham.edu.my,tkk20118@yahoo.com.sg

\begin{abstract}
The aim of the present study was to investigate the anticancer effects of crude extracts of Artabotrys crassifolius on the growth of human breast and colorectal carcinoma cell lines. The leaves and barks of Artabotrys crassifolius were extracted sequentially with hexane, chloroform and ethanol. The corresponding crude extracts obtained were then tested for their anticancer activity using MTT assay. Among the extracts studied, chloroform and hexane extracts of barks were found to possess the most potent anticancer activity which necessitates further isolation and characterisation of the bioactive compounds present in the respective extracts.
\end{abstract}

Keywords: Anticancer, Artabotrys crassifolius, Human carcinoma cell lines

\section{INTRODUCTION}

Cancer is a group of diseases characterised by uncontrolled growth and spread of abnormal cells, which can lead to death if left untreated ${ }^{1}$. The etiology of cancer can be associated with both external factors, including tobacco, infectious organisms, chemicals and radiation, as well as internal factors, such as inherited mutations, hormones, immune conditions and mutations occurring from metabolism ${ }^{2}$. These causal factors may act synergistically or sequentially to initiate or promote carcinogenesis ${ }^{3}$.

Despite the considerable progress made over the last few decades in oncology research and treatment, cancer remains as one of the foremost causes of morbidity and mortality worldwide, with 12.7 million new cases and 7.6 million deaths in $2008^{4}$. More significantly, the most common cancer treatments are restricted to surgery, radiation and chemotherapy ${ }^{5}$, which are severely fraught with challenges concerned with adverse side effects of drugs $^{6}$ due to their non-specific systemic distribution ${ }^{7}$, inadequate drug concentrations reaching the tumour ${ }^{8}$, intolerable toxicity ${ }^{9}$, and development of multiple drug resistance acquired upon repeated chemotherapeutic cycles $^{10}$. Hence, there is clearly a need for novel chemotherapeutic agents with enhanced potency and specificity.

To the best of our knowledge, no detailed studies have been reported on the pharmacological properties of Artabotrys crassifolius. Therefore, the objective in this research was to investigate the anticancer effects of crude extracts of Artabotrys crassifolius against human breast and colorectal carcinoma cell lines.

\section{MATERIALS AND METHODS}

\section{Collection and identification of plant material}

The leaves and barks of Artabotrys crassifolius, with the local name of akar mempisang, were collected from Kuala Kangsar, Perak, Malaysia $\left(4^{\circ} 46^{\prime} \mathrm{N}, 100^{\circ} 56^{\prime} \mathrm{E}\right)$ in March 2011. The plant was identified and authenticated by Mr. Kamarudin Saleh, Forest Biodiversity Division, Forest Research Institute Malaysia (FRIM). Voucher specimens were prepared and deposited in the Kepong Herbarium (KEP) of FRIM (PID 080311-05), and the School of Pharmacy, Faculty of Science, The University of Nottingham Malaysia Campus (UNMC 65) for future reference.

\section{Preparation of plant material}

After removal of extraneous matter, the freshly collected leaves and barks were air-dried in the shade at room temperature for at least 2 weeks. The dried leaves and barks were then finely pulverised by grinding prior to extraction. The pulverised leaves $(1.30 \mathrm{~kg})$ and barks $(4.79 \mathrm{~kg})$ were extracted sequentially with solvents of increasing polarity starting from hexane (Friendemann Schmidt, Australia), chloroform (Friendemann Schmidt, Australia) and 95\% (v/v) of ethanol (John Kollin Chemicals, India). Each extraction was performed in triplicate at a solid-to-solvent ratio of 1:5 (w/v) in a $40^{\circ} \mathrm{C}$ water bath (Julabo, Germany) for three days. The respective extract was subsequently filtered through qualitative filter papers No. 1 (Whatman International Ltd., England) and the collected filtrate was concentrated to dryness under reduced pressure at $40^{\circ} \mathrm{C}$ using rotary evaporator (Buchi Labortechnik AG, Switzerland). Eventually, the dried extract obtained was weighed and stored at $-20^{\circ} \mathrm{C}$ until further use. For stock solutions, each crude extract was dissolved in dimethyl sulphoxide (DMSO) ( $\mathrm{R} \& \mathrm{M}$ Chemicals, UK) at a concentration of $100 \mathrm{mg} / \mathrm{mL}$ and stored at $4^{\circ} \mathrm{C}$.

\section{Cell lines and culture media}


The cell lines used in the current study were derived from human carcinoma as shown in Table 1. Three human carcinoma cell lines were procured from the
Centre for Biomolecular Sciences, School of Pharmacy, University of Nottingham UK Campus.

Table 1: Types of human cell lines

\begin{tabular}{|l|l|}
\hline \multicolumn{1}{|c|}{ Origin } & \multicolumn{1}{c|}{ Human cell line } \\
\hline Breast carcinoma & MCF-7 (estrogen receptor-positive, ER+) \\
\hline Breast carcinoma & MDA-468 (estrogen receptor-negative, ER-) \\
\hline Colorectal carcinoma & HCT-116 \\
\hline
\end{tabular}

Each cell line was routinely maintained in Roswell Park Memorial Institute (RPMI) 1640 medium (SigmaAldrich, USA) supplemented with $2 \mathrm{mM}$ of L-glutamine (Sigma-Aldrich, USA) and $10 \%(\mathrm{v} / \mathrm{v})$ of foetal bovine serum (FBS) (Sigma-Aldrich, USA) at $37^{\circ} \mathrm{C}$ in a humidified $5 \%(\mathrm{v} / \mathrm{v})$ of $\mathrm{CO}_{2}$ incubator (Binder, Germany), and subcultured twice weekly to maintain continuous logarithmic growth.

\section{3-(4,5-Dimethylthiazol-2-yl)-2,5-diphenyltetrazolium bromide (MTT) assay}

The anticancer effects of crude extracts were investigated against human breast and colorectal carcinoma cell lines using MTT assay ${ }^{11,12}$. Each cell line was seeded in 96well microtiter plates (Jet Biofil, China) at a density of 5 $\times 10^{3}$ cells/well, and allowed to adhere for $24 \mathrm{~h}$ before crude extracts were introduced. Serial dilutions of crude extracts (final concentrations ranging from $6.25 \mu \mathrm{g} / \mathrm{mL}$ to $200 \mu \mathrm{g} / \mathrm{mL}$ ) were prepared in medium immediately prior to assay. Viable cell masses at the time of crude extract addition (time zero) and following $72 \mathrm{~h}$ exposure were determined by cell-mediated reduction of MTT. A final concentration of $400 \mu \mathrm{g} / \mathrm{mL}$ of MTT (SigmaAldrich, USA) was added to each well, and plates were incubated at $37^{\circ} \mathrm{C}$ for $4 \mathrm{~h}$ to allow reduction of MTT by viable cells to an insoluble formazan product. The well supernatant was subsequently aspirated and the cellular formazan was solubilised by addition of DMSO (R \& M Chemicals, UK) and glycine buffer ( $\mathrm{pH}$ 10.5) (SigmaAldrich, USA) in a ratio of $4: 1(\mathrm{v} / \mathrm{v})$. Eventually, the absorbance was read at $550 \mathrm{~nm}$ using an Anthos Labtec systems plate reader as a measure of cell viability.

Using the eight absorbance measurements [time zero $(\mathrm{Tz})$, control growth $(\mathrm{C})$, and test growth in the presence of crude extracts at the six concentration levels (Ti)], the percentage growth was calculated at each of the crude extract concentration levels ${ }^{13}$. Percentage growth inhibition was calculated as:

$$
\begin{gathered}
{[(\mathrm{Ti}-\mathrm{Tz}) /(\mathrm{C}-\mathrm{Tz})] \times 100 \text { for concentrations for which }} \\
\mathrm{Ti} \geq \mathrm{Tz}
\end{gathered}
$$

$[(\mathrm{Ti}-\mathrm{Tz}) / \mathrm{Tz}] \times 100$ for concentrations for which $\mathrm{Ti}<\mathrm{Tz}$

Three dose response parameters were calculated for each crude extract. Growth inhibition of $50 \%\left(\mathrm{GI}_{50}\right)$ was calculated from $[(\mathrm{Ti}-\mathrm{Tz}) /(\mathrm{C}-\mathrm{Tz})] \times 100=50$, which was the crude extract concentration resulting in a $50 \%$ reduction in the net cell growth during the incubation.
The crude extract concentration resulting in total growth inhibition (TGI) was calculated from $\mathrm{Ti}=\mathrm{Tz}$. The $\mathrm{LC}_{50}$ (concentration of crude extract resulting in a $50 \%$ reduction of initial cells at the end of the treatment as compared to that at the beginning) indicating a net loss of cells following treatment was calculated from [ $(\mathrm{Ti}-$ $\mathrm{Tz}) / \mathrm{Tz})] \times 100=-50$. Values were calculated for each of these three parameters if the level of activity was reached; however, if the effect was not reached or was exceeded, the value for that parameter was expressed as greater or less than the maximum or minimum concentration tested $^{14}$.

\section{Statistical analysis}

Statistical analysis of experimental data was performed using Microsoft Office Excel data analysis software. Data were presented by descriptive analysis as mean and standard deviation of three independent experiments performed in triplicate.

\section{RESULTS AND DISCUSSION}

Plants have an almost unlimited capacity to synthesize diverse secondary metabolites that attract researchers and scientists in the quest for new chemotherapeutics ${ }^{15}$. The continuing exploration for novel chemical classes of anticancer agents in medicinal plants is one of the realistic and promising approaches for cancer prevention $^{16}$. In the present study, MTT assay was conducted to investigate the anticancer effects of crude extracts on the growth of human breast and colorectal carcinoma cell lines.

This colourimetric assay is based on the capacity of mitochondrial succinate dehydrogenase enzymes in living cells to reduce the yellow water soluble substrate (MTT) into an insoluble, purple coloured formazan product which is measured spectrophotometrically. Since reduction of MTT can only occur in metabolically active cells, the level of activity is a measure of the cell viability ${ }^{17}$

According to the American National Cancer Institute (NCI), crude extracts could be considered as active for a $\mathrm{GI}_{50}$ value of less than $20 \mu \mathrm{g} / \mathrm{mL}^{18}$. Based on the NCI criterion, chloroform extract of barks was highly active against all of the tested carcinoma cell lines with $\mathrm{GI}_{50}$ values ranging from $4.23 \mu \mathrm{g} / \mathrm{mL}$ to $9.45 \mu \mathrm{g} / \mathrm{mL}$ (Figure 1-3). Furthermore, hexane extract of barks potently inhibited the growth of MDA-468 breast carcinoma cell line as well as HCT-116 colorectal carcinoma cell line, with respective $\mathrm{GI}_{50}$ values of $6.10 \mu \mathrm{g} / \mathrm{mL}$ and 16.45 $\mu \mathrm{g} / \mathrm{mL}$. This may indicate that the non-polar active 
principles present in the barks are responsible for the anticancer activity of this plant.

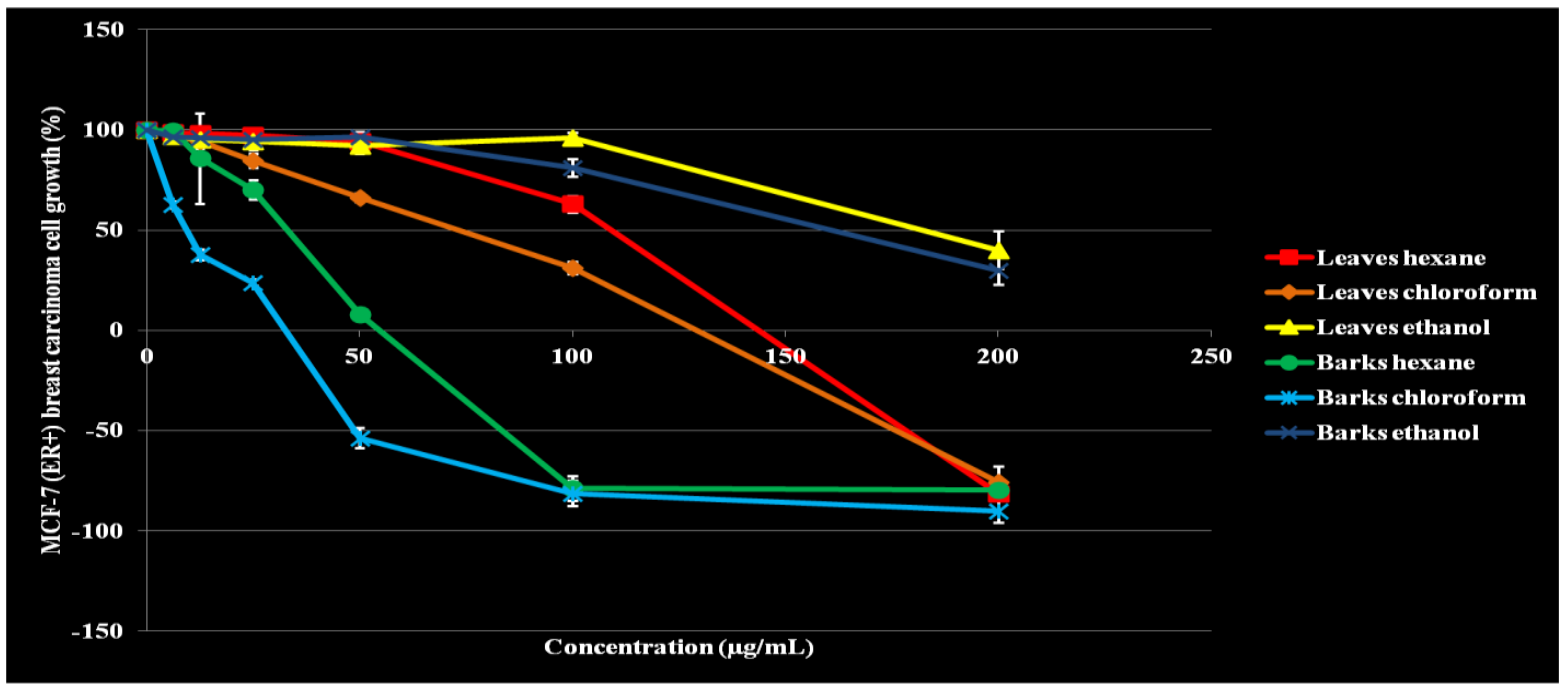

Figure 1: Effect of crude extracts of Artabotrys crassifolius on MCF-7 (ER+) breast carcinoma cell growth. Results are expressed as mean \pm standard deviation (error bar) of three independent experiments performed in triplicate, $\mathrm{n}=9$.

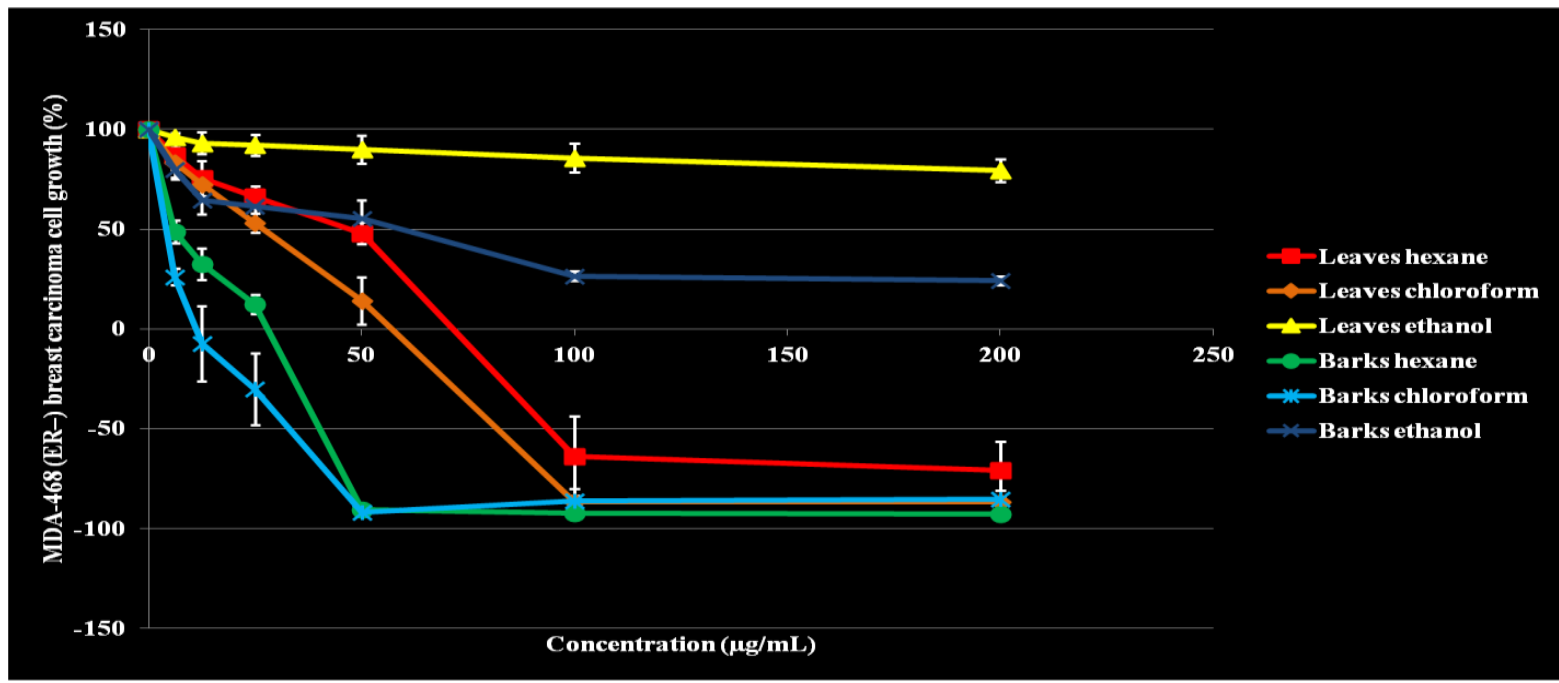

Figure 2: Effect of crude extracts of Artabotrys crassifolius on MDA-468 (ER-) breast carcinoma cell growth. Results are expressed as mean \pm standard deviation (error bar) of three independent experiments performed in triplicate, $\mathrm{n}=9$.

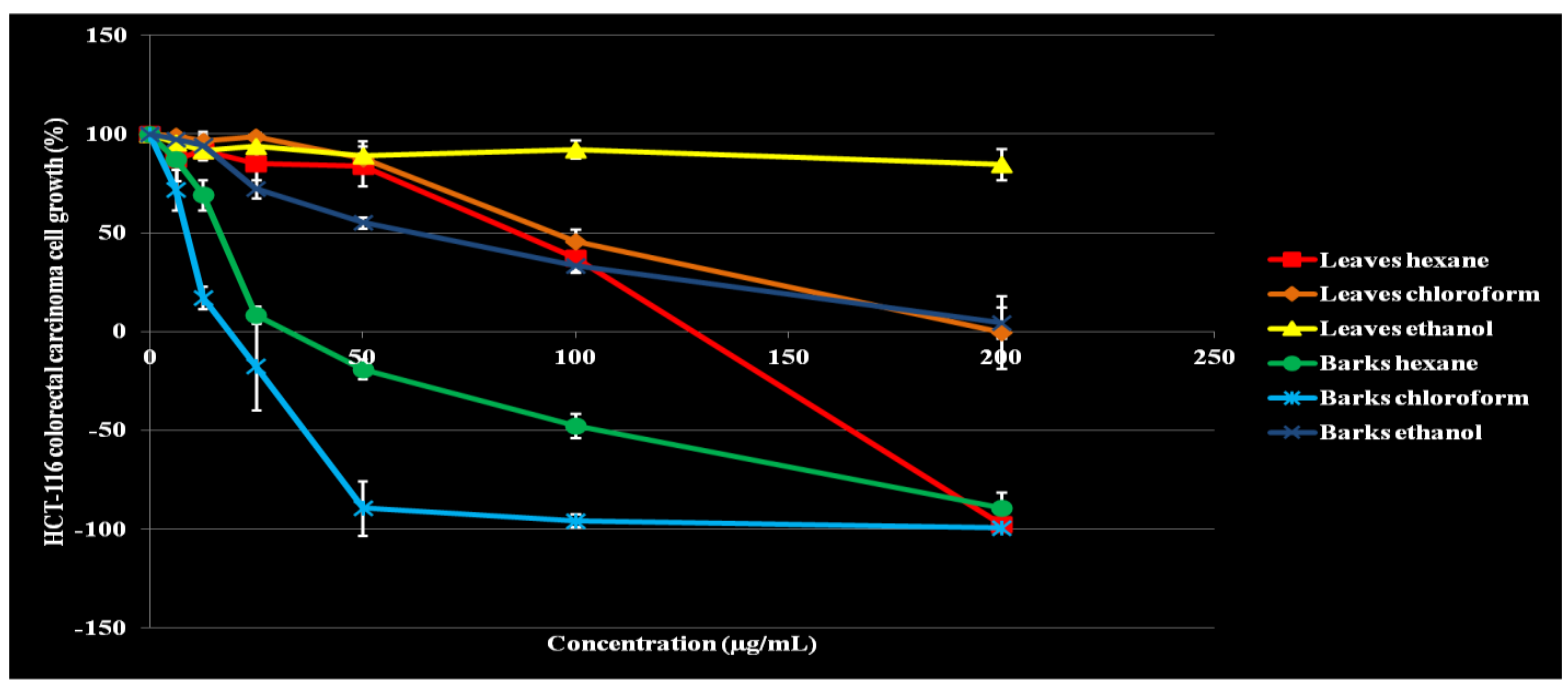

Figure 3: Effect of crude extracts of Artabotrys crassifolius on HCT-116 colorectal carcinoma cell growth. Results are expressed as mean \pm standard deviation (error bar) of three independent experiments performed in triplicate, $\mathrm{n}=9$. 
For better visualisation of the differences in achieving complete cell growth inhibition for all the crude extracts, TGI concentrations were expressed. In MCF-7 breast carcinoma cell line, chloroform and hexane extracts of barks were less potent as shown by their respective TGI values of $32.73 \mu \mathrm{g} / \mathrm{mL}$ and $54.63 \mu \mathrm{g} / \mathrm{mL}$. In MDA-468 breast carcinoma cell line, chloroform extract of barks induced total growth inhibition at the lowest concentration of $11.11 \mu \mathrm{g} / \mathrm{mL}$, whereas hexane extract of barks displayed a comparable TGI value of $28.01 \mu \mathrm{g} / \mathrm{mL}$. In HCT-116 colorectal carcinoma cell line, chloroform extract of barks exhibited a 1.75-fold lower TGI concentration than that of hexane extract of barks. However, no total growth inhibition was obtained upon treatment with ethanol extract of leaves and barks.

At doses higher than the TGIs, net cell killing was observed in all of the tested carcinoma cell lines. Chloroform extract of barks demonstrated the highest cytotoxic action with $\mathrm{LC}_{50}$ values ranging from 33.06 $\mu \mathrm{g} / \mathrm{mL}$ to $48.84 \mu \mathrm{g} / \mathrm{mL}$, while hexane extract of barks showed less pronounced cytotoxicity with $\mathrm{LC}_{50}$ values ranging from $40.14 \mu \mathrm{g} / \mathrm{mL}$ to $105.61 \mu \mathrm{g} / \mathrm{mL}$. Considering the TGI concentrations and the net cell killing achieved by crude extracts, MDA-468 breast carcinoma cell line was found to be the most sensitive cell line, followed by HCT-116 colorectal carcinoma cell

\section{REFERENCES}

1. Goyal PK. Cancer chemoprevention by natural products: current \& future prospects. Journal of Integrative Oncology, $2012,1,1$.

2. Sandeep K, Shweta, Nisha S, Manjunath SM, Arti. Combination of natural drugs: an emerging trend in cancer chemotherapy. Journal of Drug Delivery and Therapeutics, 2012, 2(3), 97-105.

3. Madan AA, Esmaeili M. Case study of geographic distribution of breast cancer in New York State. International Journal of Applied Information Systems, 2012, 4(7), 42-45.

4. Msyamboza KP, Dzamalala C, Mdokwe C, Kamiza S, Lemerani M, Dzowela T, Kathyola D. Burden of cancer in Malawi; common types, incidence and trends: national population-based cancer registry. BMC Research Notes, 2012, $5,149$.

5. Topcul MR, Cetin I. Nanotechnology in the field of clinical oncology. Marmara Medical Journal, 2013, 26, 1-4

6. Jiang S, Gnanasammandhan MK, Zhang Y. Optical imagingguided cancer therapy with fluorescent nanoparticles. Journal of the Royal Society Interface, 2010, 7(42), 3-18.

7. Drabu S, Khatri S, Babu S, Verma D. Nanotechnology: an introduction to future drug delivery system. Journal of Chemical and Pharmaceutical Research, 2010, 2(1), 171179.

8. Wang X, Wang Y, Chen ZG, Shin DM. Advances of cancer therapy by nanotechnology. Cancer Research and Treatment, 2009, 41(1), 1-11.

9. Jeyaraj M, Rajesh M, Arun R, MubarakAli D, Sathishkumar G, Sivanandhan G, Dev GK, Manickavasagam M, Premkumar $\mathrm{K}$, Thajuddin N, Ganapathi A. An investigation on the cytotoxicity and caspase-mediated apoptotic effect of biologically synthesized silver nanoparticles using Podophyllum hexandrum on human cervical carcinoma cells. Colloids and Surfaces B: Biointerfaces, 2013, 102, 708-717.

10. Shahbazi MA, Herranz B, Santos HA. Nanostructured porous Si-based nanoparticles for targeted drug delivery. Biomatter, 2012, 2(4), 296-312. line, with $\mathrm{MCF}-7$ breast carcinoma cell line being the least responsive to crude extracts.

With respect to the phytochemical screening of crude extracts $^{19}$, the presence of alkaloids, cardiac glycosides and terpenoids in chloroform and hexane extracts of barks may explain their superior activity compared to the other crude extracts tested. This necessitates further isolation and characterisation of the potentially active principles from the respective crude extracts.

\section{CONCLUSION}

Examination of the in vitro anticancer effect of Artabotrys crassifolius revealed that chloroform and hexane extracts of barks may be a significant source of novel anticancer compounds in view of their promising activities particularly against MDA-468 breast carcinoma cell line. Therefore, further studies need to be carried out to isolate and characterise the bioactive compounds responsible for the observed anticancer properties of Artabotrys crassifolius.

\section{ACKNOWLEDGMENT}

The authors are grateful to Mr. Kamarudin Saleh for plant identification and authentication.

\section{CONFLICTS OF INTEREST}

The authors declare no conflict of interest.

11. Vasselin DA, Westwell AD, Matthews CS, Bradshaw TD, Stevens MFG. Structural studies on bioactive compounds. 40.1 synthesis and biological properties of fluoro-, methoxyl-, and amino-substituted 3-phenyl-4H-1-benzopyran-4-ones and a comparison of their antitumor activities with the activities of related 2-phenylbenzothiazoles. Journal of Medicinal Chemistry, 2006, 49(13), 3973-3981.

12. Bradshaw TD, Stone EL, Trapani V, Leong CO, Matthews CS, Poele RT, Stevens MFG. Mechanisms of acquired resistance to 2-(4-Amino-3-methylphenyl)benzothiazole in breast cancer cell lines. Breast Cancer Research and Treatment, 2008, 110(1), 57-68.

13. Noolvi MN, Patel HM, Bhardwaj V, Chauhan A. Synthesis and in vitro antitumor activity of substituted quinazoline and quinoxaline derivatives: search for anticancer agent. European Journal of Medicinal Chemistry, 2011, 46(6), 2327-2346.

14. Mayer CD, Bracher F. Cytotoxic ring A-modified steroid analogues derived from Grundmann's ketone. European Journal of Medicinal Chemistry, 2011, 46(8), 3227-3236.

15. Talib WH, Mahasneh AM. Antiproliferative activity of plant extracts used against cancer in traditional medicine. Scientia Pharmaceutica, 2010, 78(1), 33-45.

16. Vijayarathna S, Sasidharan S. Cytotoxicity of methanol extracts of Elaeis guineensis on MCF-7 and Vero cell lines. Asian Pacific Journal of Tropical Biomedicine, 2012, 2(10), 826-829.

17. Mattana CM, Satorres SE, Escobar F, Sabini C, Sabini L, Fusco M, Alcaraz LE. Antibacterial and cytotoxic activities of Acacia aroma extracts. Emirates Journal of Food and Agriculture, 2012, 24(4), 308-313.

18. Hashim NM, Rahmani M, Ee GCL, Sukari MA, Yahayu M, Oktima W, Ali AM, Go R. Antiproliferative activity of xanthones isolated from Artocarpus obtusus. Journal of Biomedicine and Biotechnology, 2012, 130627.

19. Tan KK, Khoo TJ, Wiart C. Phytochemical screening of Artabotrys crassifolius Hook.f. \& Thomson (Annonaceae Juss.). Innovare Journal of Ayurvedic Sciences, 2013, 1(2), 14-17. 